\title{
Governance in the Technology Era: Implications of Actor Network Theory for Social Empowerment in South Asia
}

\author{
Akhlaque Haque $^{1}$ and Kamna L. Mantode ${ }^{2}$ \\ ${ }^{1}$ University of Alabama at Birmingham \\ ahaque@uab. edu \\ ${ }^{2}$ ACR Analytics \\ Lal. kamna@gmail.com
}

\begin{abstract}
Information and communication technologies (ICT) have proven their value in delivering time-sensitive and relevant information to targeted communities. Information has been the key resource to social development. Social entrepreneurs have leveraged ICT to reach out to people who are marginalized from public discourse. Despite successes however, some ICT initiatives have failed due to underestimating the social requirements of technology and to relying more on information systems than on the information the system transports. How information is produced and applied to a social context to create meaning is more important than the means by which it is represented through portable monitors and mobile devices. The paper argues in order to take advantage of today's ICT, it is critical that we understand how technology and society mediate within a socio-technical framework. Using the Actor Network Theory, the paper explains the process of mediation to highlight that the journey to technology-based solutions is not smooth. The Village Knowledge Center (VKC) project in India and the Access to Information (A2I) project in Bangladesh provide sound evidence of how ICT-led social development can be effective in the short run but meaningful long term changes will depend on the collaboration of social entrepreneurs and public administrators.
\end{abstract}

Keywords: Social entrepreneurship, governance, information utilization, actor network theory, public administration.

\section{Introduction}

The success of social entrepreneurship has regenerated interest in partnerships between government and civil society organizations (CSO) to solve the world's most pressing problems including, among others, dealing with demands for democratic rights, coping with climate change, and giving access to healthy living and social justice for marginalized communities. With the hopes of mobilizing citizens to become productive partners in economic revival, the international development agencies including The World Bank, United Nations Development Program (UNDP), 
the DFID (Britain), and GIZ (Germany) have invested in sustainable social development projects through collaborating with social entrepreneurs. ${ }^{1}$ Social entrepreneurship is arguably a mobilization tool used by catalytic entrepreneurs who leverage the social capital in helpless communities to develop sustainable partnership as they empower and transform the human condition (Waddock and Post, 1991; Waddock, 1991).

Information plays a critical role in motivating citizens by identifying and contextualizing information towards a purposeful goal. Indeed, democracy is strengthened by an informed citizenry as citizens take ownership of their situation to become empowered and take charge of their destiny. In this regard, information and communication technologies (ICT) have proven advantage in delivering timesensitive and relevant information to targeted communities. However, evidence suggests there are more failures than successes using ICT for social empowerment because of over reliance on the information systems rather than on the information it transports within a given social context. A systematic surveillance of the social context is a precondition to applying technology for social benefit. The paper uses actor network theory to show how linkages between human actors and the new technology can be established to form the social basis of technology deployment. Social entrepreneurs have been important catalyst in introducing new ideas through technology for social transformation. Social entrepreneurs' use of ICT for social development provides sound evidence of social mobilization using ICT.

The purpose of the proposed research agenda is to evaluate the process by which social entrepreneurs as leaders, in conjunction with public administrators, utilize information technology to activate and mobilize citizens to reach a sustainable and socially desirable outcome. For empowerment initiated through technology, the outcome depends on a complex social process independent of the technological supremacy. The growing literature on Actor Network and ethnomethodology will support discussion of the implications of action oriented information for empowerment in two independent civil society led projects in Bangladesh and India. The case studies highlight how new information that becomes available through ICT can mediate within society to build social relationships. Despite similarities in the mediation process, the approach taken by social entrepreneurs will ultimately determine the sustainability of ICT-based developments.

The paper comprises three broad sections. The first section delves into the discussions of the sociology of association as it affects our understanding of the role of technology in the larger scheme of human and non-human interaction. This section introduces Actor Network Theory (ANT). The second section connects the

${ }^{1}$ Investment in social entrepreneurship in the developed world is also noteworthy. For example, the Obama administration, through its newly created Office of Social Innovation and Civic Participation (OSICP) has allocated 1.1 billion dollars. The newly created Social Investment Fund (SIF) has given to some of America's most successful non-profit organizations to expand their work and encourage investment in health care, vocational training and direct assistance to bring people out of poverty. 
theoretical discussion of ANT to the case study on the Village Knowledge Center project in Pondicherry, India, and the Access to Information (A2I) project in Bangladesh. In conclusion, we discuss the implication of social entrepreneurship in public administration.

\section{Social Entrepreneurship and ICT}

The roots of social entrepreneurship can be traced in the works by scholars engaged in civic and community empowerment, social responsibility and social justice (Harmon, 2006; Frederickson, 1997; King, 1998); however, the role of information and information systems in the process of achieving the same goals needs further investigation. As opposed to business entrepreneurs who take risk for making new opportunities to profits, the social entrepreneurs are interested in making missionrelated social impact (Martin and Osberg, 2007; Yunus and Weber, 2010). Although a growing literature on social entrepreneurship is emerging, the creative process of leveraging resources towards social mobilization is not well understood (Dacin et. al, 2010). This becomes particularly of interest in developing countries where public agencies play a critical role in realizing the social entrepreneurial goals.

The role of ICT for social empowerment is unclear, due in part to the fact that far more ICT dependent projects fail than succeed (Goldfinch, 2007; Heeks and Bhatnagar, 1999; Korac-Boisvert and Kouzmin, 1995). Institutional impediments and failures to mobilize government support for action have often confounded ICT's role in the process (Heeks, 2005; De Rahul and Ratan, 2009). Understanding the impact of technology on social empowerment requires a deeper understanding of ICT, beyond institutional receptivity (Fountain, 2001) and into comprehension of social institutions including cultural norms and standardization of routine work (Northrop et al., 1990). These can have direct impact on the livelihood of the population in question.

Social entrepreneurs are unelected bodies who need to be competent in what they do. Competency provides one of the bases by which policy decisions are deemed legitimate (Dahl, 1970). Therefore, how to mobilize information and knowledge authoritatively in the society is a fundamental task of the social entrepreneurs. Whereas elected politicians can make value judgments about policy decisions, they have a disadvantage when it comes to gathering empirically sound, unbiased information to validate their judgments and make them acceptable to the public. The public may question the neutrality of elected officials. In addition, the qualities that helped someone win election may not always include competency in data gathering and validation (Vibert, 2007, p. 49). When it comes to policy issues, respectable social entrepreneurs and independent international development organizations can offer the skills to gather empirical evidence about what works and what does not. They can apply the technical knowledge and leverage resources specific to the mission of the development projects. However, the normative judgments about what is best for the society are reserved by the politicians; they ultimately decide what ought to be the public interest. Whereas the technocratic function (i.e. information gathering and resource mobilization) can be performed by independent social entrepreneurs, political value judgments are made by the politicians, be they liberal or 
conservative, pro-business vs. pro-liberation, or otherwise. Therefore, the social development formula in a democracy has a technocratic component for developing techniques and a political component to justify implementing projects seen as critical in maintaining a stable democracy. Social entrepreneurs can bring innovative ideas and technical knowledge to reach specific social goals. In places where development challenges have been an uphill battle due to political and/or socioeconomic situations, ICT has become an expedient tool for social connectivity and access to information hastening social mobilization and empowerment. But the process is not always clear as to how ICT can be effective in social mobilization. Actor network theory provides a framework that can be helpful to link ICT to society in general.

\section{Actor Network Theory (ANT)}

Social problems are complex and require comprehensive understanding of the relationships of the social networks and each actor's relationship to technology and the artifacts that define the socio-technical network. In other words, the society is technologically shaped as we tie ourselves to routines that are built around a network of relations to humans as well as non-human actors. Actor-Network Theory (ANT) describes how society is an assemblage of actors, each linked to create meaningful relationships. The seminal works of Bruno Latour (1987, 2005), John Law and Michael Callon $(1986,1992)$ are recognized as foundations of ANT. The subsequent work and related research within Science and Technology Studies (STS) provides further basis for understanding the evolution of ANT as a multidisciplinary study (See for example, Bijker, Hughes and Pinch, 1987; MacKenzie and Wajcman, 1999; Feenberg, 1991.) The theory asserts that the role of technology in society depends on the interpretation of the actors who use their social lenses to arrive at a mutually recognizable usage of the technology towards a given routine, while at the same time balancing their social network relationships. Technology therefore is a social construct whereby technical artifacts in society become meaningful as reliance on them becomes part of the society's routine. By way of becoming part of a societal routine, the technology is stabilized to affect social roles and relations, political arrangements, organizational structures and even cultural beliefs. Figure 1 is an attempt to describe the ANT process. The ANT defines the non-linear negotiation

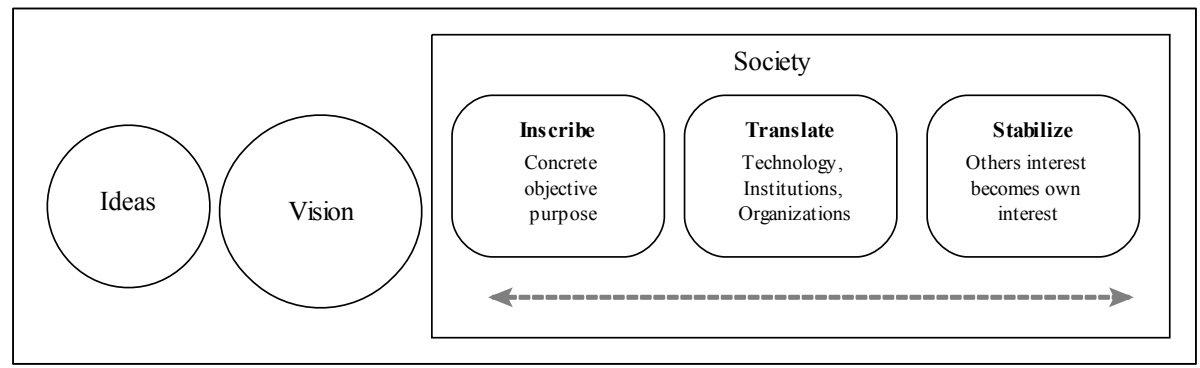

Fig. 1. Actor Network 
among differing actors as they interpret the role of other actors' (including non-human actants) which culminates to a shared mode of thinking about the normative role of technology within existing social and organizational relationship.

The figure describes, in general, the process of change within a socio-technical framework where an individual initiator of change (the actor) creates his or her own vision of the future based on understanding of the societal motives, socio-cultural and political biases, and assuming that morality, technology, science and economy will evolve in particular ways. A large part of the work of the actors involved in the initial phase of deploying an artifact is that of "inscribing" the vision or prediction about the world in the technical context of the new idea. In other words, the individual vision is combined with the technical world to meet the purpose. Until the individual idea crystalizes as an organized action, the negotiation of "idea" and "reality" continues in translation. Translation is the phase in which existing social settings including agents and institutions are aligned to meet the demands of the new idea. The evolutionary process is fraught with failures and improvisations at each stage of translation by differing actors in the process. The formal world of institutions and technology is used to translate the message (of the change) and to standardize the process so the desired change can emerge specific to the people and their context. The negotiation is said to have been resolved or standardized when one form of the initial idea appears to be acceptable by others given the human and non-human contingencies. Once the idea reaches a standard interpretation, it provides the stability and continuity required to replicate and translate it to the masses. What has been eventually "created" is the result of collective interpretation of the actors, what Heideggar (1977) calls "revealing" through "enframing" of the human mind. The essence of technology therefore, according to Heideggar, is nothing technological; it is the collective realization of transforming (revealing) idea into an art (or technè as defined by Plato; see Heideggar, 1977, p. 34) as if it is pleasing to see it from different perspectives. Therefore, technology reveals itself by meshing with the given societal norms.

The ANT's emphasis on giving equal weight to non-human actors (technology) and human actors in social development is to differentiate between situated information and objective information. Whereas, objective information is imposed on the existing social setting, situated information is applied and improvised to match the existing social norms. Translation varies with people, time and context, yet once it is stabilized it becomes part of the routine. For example, social entrepreneurs can utilize technology as a supporting element in an effort to shape the environment to favor a desired effect on a community; yet the social entrepreneurs do not have full control of the outcome given the inherent limitations within the translation phase. The outcome could be affected by, for example, differing understandings of the technology's role within existing routine. The flexibility of the translation process is directly associated with how technology may be used.

Regardless of the technological sophistication, moral reasoning as to "why do it?" must take precedence above technical rationality in the translation process. The greater the reliance on technology, not the human and cultural beliefs, to standardize the desired result, the more difficult it becomes to translate idea into action. The question of "why do it?" is answered when others' interests becomes one's own. 
Social entrepreneurs and civil society organizations provide that moral basis for initiating change. For successful implementation, however, the moral basis must also be congruent with the social values and the political judgments of the elected officials. In the translation process, the instrumental knowledge required to make the change is critical but secondary to social and political knowledge. In other words, the global knowledge must be in line with the local knowledge. This is also described as the micro-macro problem or the local-global problem in the translation process discussed in the next section (Misa, 2003). Local and global perception must be synchronized in order to sustain a stable network.

\section{Accountability of Information Technology}

The concept of ANT allows us to focus specifically on the accountability of technology to society. Just as individuals are accountable for their role in society as responsible citizens, technology must also account for its role in shaping society. That accountability can be measured by the value ICT generates through to its users. If the shared information that is gathered and disseminated among members using a particular ICT raise conflicts with the cherished values of the society, the given ICT will have a harder time situating itself in the social group. Thus, "information has an inalienable ethical dimension," noted information scientist Joseph Goguen (1997, p. 47). If technologies, such as surveillance tools, are used to compromise citizens' rights, such technologies will be incompatible with democratic values. Whether it is the right kind of information for social advancement will depend how well the ICT is able to integrate itself into the normal and acceptable routine of the social group. If the technology demands a significant shift from normal routine, adaptation will be slower and the failure rate will increase to the point where the user critical mass will not be sufficient to have significant impact in social behavior. It becomes incumbent that the local actors embrace ICT for their social advantage, and for that, global actors should pay adequate attention to the social-self of the local actors. Otherwise, the local-global conflict will destabilize a negotiated network.

How fast the local actors embrace a particular technology has to do with the type of technology introduced in the early phases of technology deployment. Elected representatives often fail to address the social value of ICT, particularly if they are deployed in large scale. In the absence of actions from elected representatives, social entrepreneurs can easily fill the void by bringing pertinent ideas of social mobilization using technological means. As Waddock (1991) carefully noted: "Social entrepreneurs generate followers' commitment to the project by framing it in terms of important social values, rather than purely economic terms, which results in a sense of collective purpose [Burns, 1978] among the social entrepreneur and those who join the effort" (p. 394).

Social entrepreneurs capitalize on a local network to earn trust as they focus on a target population to address pertinent social concerns. They leverage social capital to articulate larger, complex social problems within the task environment (concept coined by Thompson [1967]). Aiding the process of translation are intermediaries, 
technical resources employed to mobilize the actors. Examples of intermediaries can be maps, policy documents, mobile apps and even financial resources which symbolize a social order and power in the network. The intermediaries aid in the translation by standardizing the message across time and place. Inscriptions like "reports, texts and documents refer to the way technical artifacts embody pattern of use" (Rhodes, 2009). Government can play a key role in facilitating development of intermediaries. Modern day internet and ICT in general are powerful intermediaries, providing standardized platforms to expedite e-government services (paying taxes, getting licenses, online procurement, etc.) and other useful functions. Intermediaries are passive when it comes to transforming the social order to address larger socioeconomic concerns such as poverty, social equity and social justice issues.

Unlike intermediaries, mediators transform the message as opposed to just transport it without distortion or addition. ${ }^{2}$ With respect to mediators, when a message is being transported, it customizes it based on local context. Therefore mediators impede standardization of the message as it finds ways to channel the message through improvisation to address the needs of the day.

While clearly the internet and ICT in general are effective intermediaries; they can also be powerful mediators when used to disseminate situated information for social transformation. Intermediaries are the primary vehicles for creating "blackboxes" or closed systems where the input leads to a given output and the interlocking of the coordination between input and output is not clearly identified (Kaghan and Bowker, 2001). When a network or part of the network is successfully black-boxed, it can be treated as a simple input/output device that is expected to perform a routine operation with precision and without creating any disturbances within the larger system. Since black boxes work with near certainty, they can be transferred from one black box to another set or subset of black boxes. They can be effectively used to mobilize an individual or group to mediate in addressing larger socioeconomic concerns such as poverty, social equity and social justice issues. For example, social media tools (targeted apps, twitter, Facebook, etc.) can be powerful intermediaries to mobilize a large mass for a certain cause. The masses can then become mediators to make changes on the ground or even utilize the same social media tools to startoff another series, effectively mobilizing another group of masses for some other cause. Look for example at "the Arab Spring" of 2012 and subsequent movements in Libya, Syria and other parts of the world. What intermediary is to technique is what mediator is to act on that technique for specific solutions. The two case studies refer in this paper highlight how information technology can become an active "social tool" to change the human condition as local actors utilize the tools of their daily social routine for expanded purpose. With the help of global actors such as social entrepreneurs and governmental agencies who provide technical or political or moral support, technology can be an effective tool to mobilize social empowerment.

\footnotetext{
${ }^{2}$ A good discussion about intermediaries and mediator can be found in Latour (2005), pp. 3742.
} 


\section{$5 \quad$ Information Technology and Society: Case Studies}

\subsection{Village Knowledge Center Project (VKC), India}

The Village Knowledge Center project started as a pilot initiative in 1998 in Pondicherry, India, a rural region that was once a French colony in the southern state of Tamil Nadu. The project was initiated by the M. S. Swaminathan Research Foundation (MSSRF), a rural development nonprofit organization founded by Professor M. S. Swaminathan in 1988. Among many different projects undertaken by MSSRF, the village center project is of particular interest to this study because it systematically blends technology with social context for social development. The materials for the case study are gathered from the work of Swindell (2006, 2007), Bhatnagar et.al., (2006), published reports by the MSSRF (Senthikumaran S. and Arunachalam, 2002; Nanda and Arunachalam, 2009) and the archived reports from the official website of MSSRF http://www.mssrf.org.

The vision of the MSSRF projects is to increase the capacity of the marginalized communities in the rural areas through community-demand driven technology. At the initial phase of the VKC project, a need assessment survey was conducted in the target area of Pondicherry to find what the local people already knew about the resources available to them and what they needed to know to improve their livelihood. Rather than creating a new technology-driven system, technology was brought in to improve upon the existing socio-technical design. There was clear methodology about how to create Village Knowledge Centers, methodology which was refined over more than 10 years. A large group of volunteers have been trained to maintain and operate the VKCs. A detailed handbook titled Toolkit for setting up Rural Knowledge Centers $(R K C)$ is widely circulated to standardize the process. Once established, VKCs worked as the information hub for a several communities. For example, the farmers had incomplete or, in some cases, no information about market prices for their crops. Fishermen had no scientific way to forecast the weather or their prospects for good fishing the next day. Technology helped deliver such information through very high frequency radio wave broadcast within a 12 kilometer radius. Technology also enabled voice data transfer to be converted to text and then to fax out which then was uploaded and displayed on a computer screen.

The village centers were initially housed in private residences with limited access to all farmers, particularly those belonging to the lower caste, poor communities. Inability to ensure equitable access to all the farmers was seen a major obstacle for mobilizing the local network. Once MSSRF recognized the drawback, they had to revisit the strategy. They closed the village information centers after a few months. When they reintroduced the project with a revised action plan, they also established VKCs for an additional 12 villages.

Participation in VKCs was contingent on an expressed request of the village community. Also the village community was required to provide premises in a public building and to ensure the center was accessible to everyone in the village. In most cases these centers were located in public places like temples, government offices, noon meal program centers and panchayat (village assembly) office. The village 
community was responsible for the upkeep of the rooms and utility bills. Finally, every village was also required to provide local volunteers who were trained by the foundation staff and placed in the centers to function as information facilitators, computer maintenance experts and local information gatherers. In order to establish and stabilize the new information gathering method, a great number of volunteers, especially women, were trained in basic PC operations, use of data cum voice networks, maintenance of user log register, management of queries and handling data requests. Involving the village community from the beginning and encouraging local people to take ownership of the VKC was critical to the longevity of the project. Involvement was essential to drive the amount of social impact necessary to empower people in the communities through information and knowledge sharing. In terms of power, the global network represented by MSSRF was scaling back its control when it allowed the villages to control the location and provide the volunteers. By providing autonomy to the local network, MSSRF was able to mobilize and strengthen stakeholders in the implementation of the project. Transferring ownership was critical for building trust among global and local networks. VKCs clearly focused on situational information as opposed to objective information, and this helped the citizens to incorporate technology into their daily routine. The new technology was able to earn trust which in turn speeded deployment to larger groups. The special value of this project is the manner in which local knowledge was given importance. In particular, for example, all information including databases was translated into the local Tamil language. A variety of visual multimedia resources were also used to standardize the message.

The VKCs vision and commitment to learning and engaging the poor attracted the support of the Indian government in the form of a monetary grant of 100 core rupees and technical support from Indian Space Research Organization (ISRO) for launching a separate satellite for the program. Under the National Virtual Academy (NVA) program women empowerment groups are being trained in organic farming, herbal healing. Self-help groups also hold regular video conferences with rural communities and experts, manufacturers, government officials and experts. Fishermen are being offered training in the use of GPS and fish finding equipment. NVA launched a program called "Knowledge on Wheels" in 2007, in partnership with the Sankara Nethralaya Medical Research Foundation. The purpose of the project is to provide eye care information and eye care facilities to the rural poor. In collaboration with Hindustan Petroleum and ISRO, NVA has plans to use a mobile soil testing van that will help to detect the chemical composition of soil, including its $\mathrm{pH}$ and availability of various nutrients. This mobile equipment can propagate knowledge about crop cultivation, livestock management and harvesting technologies to locations not yet connected to permanent centers. NVA also plans to help educate villagers on methods of agro packaging. In collaboration with Bosch, a machine is made available to NVA for them to use for demonstrations across the villages to spread knowledge about hygienic packaging.

In 2004, MSSRF created a multiple stakeholder ICT partnership labeled as "Mission 2007: Every Village a Knowledge Centre". The target for this partnership was to connect 600 thousand villages via internet and radio communication by the year 2007. In 2007 , 
global partners of MSSRF Microsoft and Telecenter.org (a joint effort of Microsoft, IDRC, Canadian and Swiss development agencies constituted a rural innovation fund (RIF). The sole purpose of this fund is to provide resources for development of technologies customized to fit the needs of rural population and their development. In particular, the mission of the fund is to encourage technology entrepreneurs. The response to RIF was encouraging; of the 1400 applications received, 9 software programs have been developed by the project. The software applications range from an ecommerce web portal, to animal husbandry, to account maintenance for self-help groups. As of 2009, MSSRF had Village Knowledge Centers in 5 states of India: Tamil Nadu, Kerala, Orissa, Maharashtra and Pondicherry, in total about 101 village knowledge centers and 15 village resource hubs.

\subsection{Access to Information (A2I) Project - Bangladesh}

A2I is the one of the largest technology-driven initiatives undertaken by the United Nations Development Program to expand e-Services capacity for the Government of Bangladesh (GoB). The A2I initiative used a grassroots approach to training and educating a critical mass of government officials, individual entrepreneurs and volunteers in ICT to create ICT-driven services (e-Services) at the door steps of citizens. Initially launched in 2009 , the overall goal of the project is to create an eService environment to provide access to information and services that can reach the most vulnerable population in society. Unlike the Village Knowledge Centers discussed earlier, the A2I partnered with the government from the beginning of the project. This approach not only mobilized resources quickly but also placed the large governmental apparatus at the disposal of the A2I initiative. The primary information discussed in this paper about A2I is gathered from reports published by UNDP (2012) and reports published on the official A2I website by the Government of Bangladesh (http://a2i.pmo.gov.bd/index.php).

The A21 project aimed to utilize situated information to build capacity for local actors and give them ownership for sustainable e-Services throughout the country. The GoB took the A2I as one of their own projects as it was synonymously identified with the "Digital Bangladesh" goal within the national development agenda declared by the current government. The project attracted a large critical mass through its Quick Wins (QW) e-Services projects. Quick Wins is referred to e-Services that could be quickly developed to facilitate citizen government interaction at the grass root level to work at the district, Upazila (regional jurisdiction) and village levels to create accessibility infrastructure. In the first two years of the project, $53 \mathrm{QW}$ eservice projects encompassing 9,000 independent entrepreneurs trained to run and manage over 4,500 Union Information and Service Centers (UISC), were begun, covering the whole country. Currently, there are $700 \mathrm{QW}$ projects in the pipeline.

A notable outcome of the project has been the development of multimedia classrooms in some 500 schools. This is expected to be scaled up to 15,000 secondary schools within two years. The following table highlights some of the signature QW projects that are significant due to their social impact on ordinary citizens of the country. 
Table 1. Impact of Popular A2I-Quick Win Initiatives

\begin{tabular}{|c|c|}
\hline Initiative & Impact \\
\hline $\begin{array}{l}\text { UISC (Union } \\
\text { Information } \\
\text { Service Center) }\end{array}$ & $\begin{array}{l}\text { Three million users have access to growing e-service } \\
\text { portfolio; saves citizens time \& money through reduction in } \\
\text { travel } 3 \mathrm{M} \text { grassroots people/month generating } \\
\$ 150 \mathrm{~K} / \mathrm{month}\end{array}$ \\
\hline $\begin{array}{l}\text { DESC (District E- } \\
\text { service center) }\end{array}$ & $\begin{array}{l}\text { Significant reductions in delay (time for certified document } \\
\text { reduced by half); } 50 \% \text { more requests processed per day; } \\
\text { more transparent } 5,000 \text { applicants/month }\end{array}$ \\
\hline $\begin{array}{l}\text { Multimedia } \\
\text { Classroom }\end{array}$ & Students interest in lessons increased $50 \%$ \\
\hline $\begin{array}{l}\text { E-Purjee (Digital } \\
\text { Cane Procurement } \\
\text { System) }\end{array}$ & $\begin{array}{l}\text { Over } 200,000 \text { sugar cane farmers benefitting from more } \\
\text { transparent system where they are informed of when to } \\
\text { deliver sugar (in the past they sometimes never received the } \\
\text { paper "chalan", or had to pay rent seekers a fee or travelled } \\
\text { to the mill in vain) and when they will be paid; mills are } \\
\text { benefitting from more efficient delivery }\end{array}$ \\
\hline
\end{tabular}

Source: UNDP, 2011

Over 200,000 sugar cane farmers benefit from a more transparent system through which they are informed of the best time to deliver sugar and when they will be paid. In the past the farmers sometimes failed to receive the paper (chalan) or they were obliged to pay a fee for information to unscrupulous petty officials. Sometimes the farmers traveled to the mill in vain. The new system to disseminate accurate information in a timely manner minimizes such problems. Mills too receive benefits from more efficient delivery

One of the unique features of the project was to enroll top level bureaucrats, senior government officials at the ministerial/federal level, public representatives and local entrepreneurs in ways that made them aware and informed about the developing services. Therefore they felt less threatened by the new means of governing-from-a-distance (eServices). Awareness was followed by ownership which was fundamental in the translation phase to mobilize citizens towards using any particular e-Service activity. For example, all Ministries had to come up with their own Quick Win projects that were tied to the existing infrastructure of ongoing A2I projects. Although ministries varied in terms of their competency and commitment for such projects, there was a sense of pride among peers when a particular e-Service was launched and citizens embraced those services. The A2I project has interested many businesses and international donor organizations including the World Bank, Intel, International Rice Research Institute, D.Net, Asian Development Bank, UNESCO and UNICEF. 


\subsection{Policy Implications of VKC and A2I}

We can glean very important insights from these two projects. First, the application of technology must directly address the fundamental matter of improving the quality of life of the local actors even if the new activity appears to be trivial or mundane in the eyes of the global actors, i.e., social entrepreneurs or the government. The technology adaptation can be smoother when the normal routine within the social association remains undisturbed. This is critical because during the translation phase when the new technology is introduced the actors can easily negotiate common definitions and meanings of the new way of doing things. Second, rather than introducing a big change through a big project, a gradual and incremental approach can have a wider and more meaningful impact in the society. This is because by keeping things simple, the standard definition can be easily and quickly replicated to serve greater numbers of people in a greater variety of small ways. For example, thorough the Quick Win projects for A2I in Bangladesh, the farmers were not learning anything new about farming, but they were getting valuable information quickly at insignificant cost. This enabled the farmers to focus on increasing production and diversifying their greater earnings to invest in other productive uses, perhaps for their children's education or for beginning a small handicraft business.

The VKC project in India started as a small scale, pilot investment in private homes. Within the first few months of operation the problems were revealed within the existing infrastructure regarding lack of access by potential beneficiaries within the lower caste population. We note that technology must be adjusted and in some case improvised in order to meet the demands of the existing socio-cultural circumstances. Whereas technical adjustment can be easier, especially when undertaken in smaller scale, value adjustments take time and may be difficult without political support. When technocratic functions are imposed without regard to both political and sociocultural context, a high failure rate is inevitable, at least when measured in terms of usage and mobilization. Whether the global actors are NGOs or governments, the values of the local actors involved must take precedence to the values or demands of the global actors. As argued earlier, the greater the supremacy of technology in the design of a project over the values that justify the project, the more difficult it becomes to translate the idea into action. Technology cannot address questions of values. Therefore, the ideals of democracy, freedom and justice must be addressed through avenues that deal with empowerment and awareness of the citizens' limitations. Information technology has proven that it can mobilize and empower the citizenry.

The deep rooted caste system that pervades rural India provided the impetus for the global actors (social entrepreneurs) to intervene to override the societal bias via information technology tools. Values drove the strategy and design of the Village Knowledge Centers to introduce technological tools for the benefit of all citizens. VKCs placed technology in the role of a mediator, less as an intermediary, and that effective policy enabled the VKCs to address social bias and help to empower masses that had been marginalized. 
Similarly, in Bangladesh where political turmoil and corruption impede social development, social entrepreneurs intervened and played a dominant role in transforming the way the central government and its local counterparts ran their business. By partnering with international NGOs, the social entrepreneurs were able to break through political barriers to reach out to citizens via Quick WIN projects. The applications (apps) are more often intermediaries than mediators. Whereas in India technology was able to mediate deep into the social prejudices and the culture; Bangladesh was able to solve a problem quickly and to replicate the simple model exponentially to deliver accessible benefits widely throughout the country. The extent of the cultural shift which was very apparent in Pondicherry may not be as apparent in Bangladesh, at least in the short run, but both case studies reveal Actor Network Theory succeeding to improve the quality of life through applications of technology. In both cases the values and realities of the citizen beneficiaries informed the design and implementation of the technological tools.

The balance of societal values with functional abilities of technology is a promising formula for success, yet all projects are vulnerable. Many of the gains brought about by the social entrepreneurs, NGOs, or any global actors can easily be undermined unless vigilant and engaged public administrators act on behalf of the local citizens. For example, in India the elite class may find it to their advantage to reinforce historical norms of social discrimination and devise means to incapacitate the VKCs. The sustainability of the VKCs will depend on how effectively local citizens take ownership of the centers' mission and services. Should they be blinded to the advantages or doubtful of their need to be involved, they may withdraw their support and see the demise of the project. In Bangladesh, diligent oversight by village citizens and the public managers who represent their interests may well be necessary to protect the large scale, widely uniform ICT projects from abuse by ruling political parties who can misuse the projects for their own political gain. To compound the risks, successful projects can and do attract the attention of national or even international interests with no regard to the quality of life of the participating local actors. Projects are vulnerable to sophisticated hijacking orchestrated by distant powers who can exploit the local citizens. Anecdotal evidence suggests that both VKCs and A21 projects are becoming vulnerable to some or all of these intrinsic risk factors. Public administrators have the responsibility to monitor and maintain the innovative projects that have direct social and economic implications for their societies.

\section{Conclusion}

Information technology plays a critical role in balancing our life and work in society today. Applications of technology are instrumental in shaping our values as we develop a deeper understanding of the roles they can take in all aspects of our lives. The modern era has seen a sudden shift towards ICT-based policy developments, a shift with wide ranging implications in our social and economic life. Being in the midst of the transition, the millennia generation may take for granted the changes without questioning how the social and economic values have shifted in response to ICTs role in society. 
Information technology enthusiasts have long argued that ICT is an empowerment tool and liberator for the marginalized. They argue, by introducing ICT into the governing process (i.e., automation of service delivery through E-Government) government can be accessible and convenient for citizens. Indeed today government is much closer to citizens through electronic means and is probably more transparent as far as service delivery is concerned. Even so, whether the citizens are empowered in the sense of taking control of their own livelihood is debatable. Societal empowerment demands sustainable social and economic development for all people including the most vulnerable populations. Technology can be the mediator for connecting citizens, but it cannot be the translator for action. Action requires the support of global network visionaries who help to mobilize the local citizenry network.

In the information age, implications of this study for public managers must not be underestimated. Public administrators, as non-elected representatives, occupy the desks where citizens come to ask for what they need their government to do; yet public administrators are bounded by procedures that are often antithetical to empowerment of the citizens who stand before them. Restricted by limitations of their ability to reach out to citizens, public managers can use ICT as the mediator to deliver an essential resource, information, to the doorsteps of citizens who will use it. Unlike food that will almost certainly be consumed when provided to the hungry, information may not be readily consumed. Potential beneficiaries require strategic direction about where and how to use the information. They need to comprehend the benefits of using the new information. In other words they ask, "What's in it for me?" When the "fundamental purpose of social entrepreneurship is creating social value for the public good," (Christie and Honig, 2006, p.3) it is only fitting for public administrators to answer that question and align with such a cause that brings social value to the public.

As our study alludes, social entrepreneurs provide the vision for information resources to be utilized for individual advantage. In the absence of visionaries within the local elected representatives, public administrators can partner with social entrepreneurs and civil society organizations. In the U.S., organizations such as Imagine Chicago (http://www.imaginechicago.org) and Everyday Democracy (http://www.everyday-democracy.org) have provided exemplary social entrepreneurial leadership within their communities.

Zukin et al. (2006) points out, "citizens need to be able to engage in the institutions and process of government and of civil society, since both are authoritative determiners of how goods, services, and values are allocated in a society" (p. 207). Today civic participation is an integral part of democracy, but it is open to question whether awareness of government and of political issues and participation in government services are constructive within the society. Leadership from public administrators dedicated to represent the citizens is crucial. Public administrators and public managers will best succeed in their efforts to deliver service when they accurately assess the local situation - the abilities, impediments, cultural mores and values -- and devise strategies to serve the citizens through technologies designed with the local situation in mind. Indeed, what is needed is an intention and desire to change the nature of the relationships amongst and between citizens and government. Some initial relationships may have to come from active citizens who will mobilize the resources towards a sustainable, beneficial impact in our communities. 


\section{References}

Bhatnagar, D., Dewan, A., Torres, M., Kanungo, P.: M.S. Swaminathan Research Foundation's Information Village Research Project (IVRP). Union Territory of Pondicherry, World Bank (2003)

Bijker, W.E., Hughes, T.P., Pinch, T.J. (eds.): The Social Construction of Technological Systems, New Directions in the Sociology and History of Technology. MIT Press, Cambridge (1987)

Callon, M.: Some Elements of a Sociology of Translation: Domestication of the scallops and the fishermen of St Brieuc Bay. In: Law, J. (ed.) Power, Action and Belief: A New Sociology of Knowledge, pp. 196-233. Routledge \& Kegan Paul, London (1986)

Dacin, P.A., Dacin, M.T., Matear, M.: Social Entrepreneurship: Why We Don't Need a New Theory and How We Move Forward From Here. Academy of Management Perspectives 24(3), 37-57 (2010), doi:10.5465/amp.2010.52842950

Dahl, R.A.: After the revolution; authority in a good society. Yale University Press, New Haven (1970)

De, R., Ratan, A.L.: Whose gain is it anyway? Structurational perspectives on deploying ICTs for development in India's microfinance sector. Information Technology for Development 15(4), 259-282 (2009), doi:10.1002/itdj.20129

Feenberg, A.: Critical Theory of Technology. Oxford University Press, New York (1991)

Fountain, J.E.: Building the virtual state: Information technology and institutional change. The Brookings Institution, Washington (2001)

Frederickson, H.G.: The spirit of public administration. Jossey-Bass Publishers, San Francisco (1997)

Goguen, J.: Social Theory of Information. In: Bowker, G.C. (ed.) Social Science, Technical Systems, and Cooperative Work: Beyond the Great Divide, pp. 27-56. Lawrence Erlbaum Associates, Mahwah (1997)

Goldfinch, S.: Pessimism, Computer Failure, and Information Systems Development in the Public Sector. Public Administration Review 67(5), 917-929 (2007)

Harmon, M.M.: Public Administration's Final Exam: A Pragmatist Restructuring of the Profession and the Discipline. University of Alabama Press (2006)

Heeks, R.: ICTs and the MDGs: On the Wrong Track? Information for Development, III(3). Retrieved from ICTs and MDGs in Wrong Track website (2005), http: / / www. sed.man.ac.uk/idpm/research/publications / wp / di / sho rt/di_sp07.pdf

Heeks, R., Bhatnagar, S.: Understanding success and failure in information age reform. In: Heeks, R. (ed.) Reinventing Government in the Information Age: International Perspectives in IT-Enabled Public Sector Reform, pp. 49-74. Routledge, London (1999)

Heeks, R., Seo-zindy, R.: ICTs and Social Movements under Authoritarian Regimes: An ActorNetwork Perspective. Centre for Development Informatics, Institute for Development Policy and Management, SED, Manchester, UK (2013)

Heidegger, M.: The question concerning technology, and other essays. Harper \& Row, New York (1977)

Kaghan, W.N., Bowker, G.C.: Out of machine age?: complexity, sociotechnical systems and actor network theory. Journal of Engineering and Technology Management 18(3-4), 253269 (2001), http: / / dx. doi.org/10.1016/S0923-4748

King, C.S., Stivers, C., Box, R.C.: Government is us: public administration in an antigovernment era. Sage Publications, Thousand Oaks (1998) 
Korac-Boisvert, N., Kouzmin, A.: Transcending soft-core IT disasters in public sector organizations. Information Infrastructure and Policy 4(2), 131-161 (1995)

Latour, B.: Science in action: How to follow scientists and engineers through society. Harvard University Press, Cambridge (1987)

Latour, B.: Reassembling the social: an introduction to actor-network-theory. Oxford University Press, Oxford (2005)

Law, J.: Notes on the Theory of the Actor-Network: Ordering, Strategy and Heterogeneity. Systems Practice 5, 379-393 (1992)

Law, J., Callon, M.: The Life and Death of an Aircraft: A Network Analysis of Technical Change. In: Bijker, W.E., Law, J. (eds.) Shaping Technology/Building Society: Studies in Sociotechnical Change, pp. 21-52. MIT Press, Cambridge (1992)

MacKenzie, D.A., Wajcman, J.: The social shaping of technology. Philadelphia: Open University Press, Buckingham (1999)

Martin, R.L., Osberg, S.: Social entrepreneurship: the case for definition. Stanford Social Innovation Review 5(2), 28 (2007)

Misa, T.J., Brey, P., Feenberg, A.: Modernity and Technology. MIT Press (2003)

Nanda, S., Arunachalam, S.: Reaching the Unreached. M S Swaminathan Research Foundation, Chennai (2009)

Northrop, A., Kraemer, K.L., Dunkle, D., King, J.L.: Payoffs from Computerization: Lessons over Time. Public Administration Review 50(5), 505-514 (1990)

Rhodes, J.: Using Actor-Network Theory to Trace an ICT (Telecenter) Implementation Trajectory in an African Women's Micro-Enterprise Development Organization. Information Technology and International Development 5(3), 1-20 (2009)

Swindell, J.: The Information Villages of Pondicherry: a case study in capacity building for sustainable development. In: Leal, W. (ed.) Innovation, Education and Communication for Sustainable Development, pp. 515-534. Peter Lang., Frankfurt (2006)

Swindell, J.: Rural empowerment through access to knowledge: a comparison of two projects on two continents. Paper Presented at the European Federation for Information Technology in Agriculture (EFITA), Glasgow, England (2007)

Thompson, J.D.: Organizations in Action: Social science bases of administrative theory. Transaction Publishers, New Brunswick (2003)

UNDP, Bangladesh: Access to Information (A2I) Evaluation (5398). Dhaka, Bangladesh: United Nations Development Programme, UNDP (2011), http: / / erc . undp. org/evaluationadmin/downloaddocument. html ? doc id $=5398$ (retrieved)

Vibert, F.: The rise of the unelected: democracy and the new separation of powers. Cambridge University Press, Cambridge (2007)

Yunus, M., Weber, K.: Building social business: the new kind of capitalism that serves humanity's most pressing needs. Public Affairs, New York (2010)

Zukin, C., Keeter, S., Andolina, M.W., Jenkins, K., DelliCarpini, M.X.: A new engagement? Political participation, civic life, and the changing American citizen. Oxford University Press, New York (2006) 